\title{
HYPOTHERMIC RETROGRADE VENOUS PERFUSION WITH ADENOSINE COOLS THE SPINAL CORD AND REDUCES THE RISK OF PARAPLEGIA AFTER THORACIC AORTIC CLAMPING
}

Scott D. Ross, MD

John A. Kern, MD

James J. Gangemi, MD

Char R. St Laurent, REEGT

Kimberly S. Shockey, MS

Irving L. Kron, MD

Curtis G. Tribble, MD
Objective: We evaluated the utility of retrograde venous perfusion to cool the spinal cord and protect neurologic function during aortic clamping. We hypothesized that hypothermic adenosine would preserve the spinal cord during ischemia. Methods: Six swine (group I) underwent thoracic aortic occlusion for 30 minutes at normothermia. Group II animals underwent spinal cooling by retrograde perfusion of the paravertebral veins with hypothermic $\left(4^{\circ} \mathrm{C}\right)$ saline solution during aortic occlusion. The spinal cords of group III animals were cooled with a hypothermic adenosine solution in a similar fashion. Intrathecal temperature was monitored and somatosensory evoked potentials assessed the functional status of spinal pathways. Results: Spinal cooling without systemic hypothermia significantly improved neurologic Tarlov scores in group III $(4.8 \pm 0.2)$ and group II $(3.8 \pm 0.4)$ when compared with group I scores $(1.3 \pm 0.6)(P<.001)$. Furthermore, 5 of the 6 animals in group III displayed completely normal neurologic function, whereas only one animal in group II and no animals in group I did $(P=\mathbf{. 0 0 5})$. Somatosensory evoked potentials were lost $10.6 \pm 1.4$ minutes after ischemia in group $I$. In contrast, spinal cooling caused rapid cessation of neural transmission with loss of somatosensory evoked potentials at $6.9 \pm 1.2$ minutes in group II and 7.0 \pm 0.8 minutes in group III $(P=.06)$. Somatosensory evoked potential amplitudes returned to $85 \%$ of baseline in group III and $90 \%$ of baseline in group II compared with only $10 \%$ of baseline in group I $(P=.01)$. Conclusions: We conclude that retrograde cooling of the spinal cord is possible and protects against ischemic injury and that adenosine enhances this effect. The efficacy of this method may be at least partly attributed to a more rapid reduction in metabolic and electrical activity of the spinal cord during ischemia. (J Thorac Cardiovasc Surg 2000;119:588-95)
Since the first thoracoabdominal reconstructions for - aneurysmal disease and related pathologic conditions were done in the early 1950s, the risk of devastat-

From the Department of Surgery, Division of Thoracic and Cardiovascular Surgery, University of Virginia Health Sciences Center, Charlottesville, Va.

Read at the Seventy-ninth Annual Meeting of The American Association for Thoracic Surgery, New Orleans, La, April 18-21, 1999.

Received for publication April 1, 1999; revisions requested July 12, 1999; revisions received Sept 8, 1999; accepted for publication Oct 22, 1999 .

Address for reprints: Curtis G. Tribble, MD, Department of Surgery, Division of Thoracic and Cardiovascular Surgery, University of Virginia Health Sciences Center, Box 3111, MR4 Building, Charlottesville, VA 22908 (E-mail: cgt2e@aol.com).

Copyright @ 2000 by Mosby, Inc.

0022-5223/2000 $\$ 12.00+0 \quad \mathbf{1 2 / 6 / 1 0 4 0 3 9}$

doi: $10.1067 / \mathrm{mtc} .2000 .104039$ ing neurologic injury to the spinal cord has continued to threaten the outcome of these complex procedures. More sophisticated techniques and repairs have certainly led to a decline of the incidence of paraplegia and paraparesis over the years, but unfortunately the risk of irreversible spinal cord injury still exists. Recent surgical series continue to document permanent spinal cord dysfunction in $1.5 \%$ to $16 \%$ of cases of thoracic and thoracoabdominal aortic reconstructions. ${ }^{1-6}$

The pathophysiology of spinal cord ischemic injury is clearly multifactorial. The fundamental causal factor is reduced spinal cord blood flow distal to the segment of occlusion. In addition, a series of interdependent events, including proximal hypertension, increased cerebrospinal fluid (CSF) pressure, distal hypotension, interruption of blood flow to the critical intercostal or lumbar arteries, duration of aortic clamping, extent of 


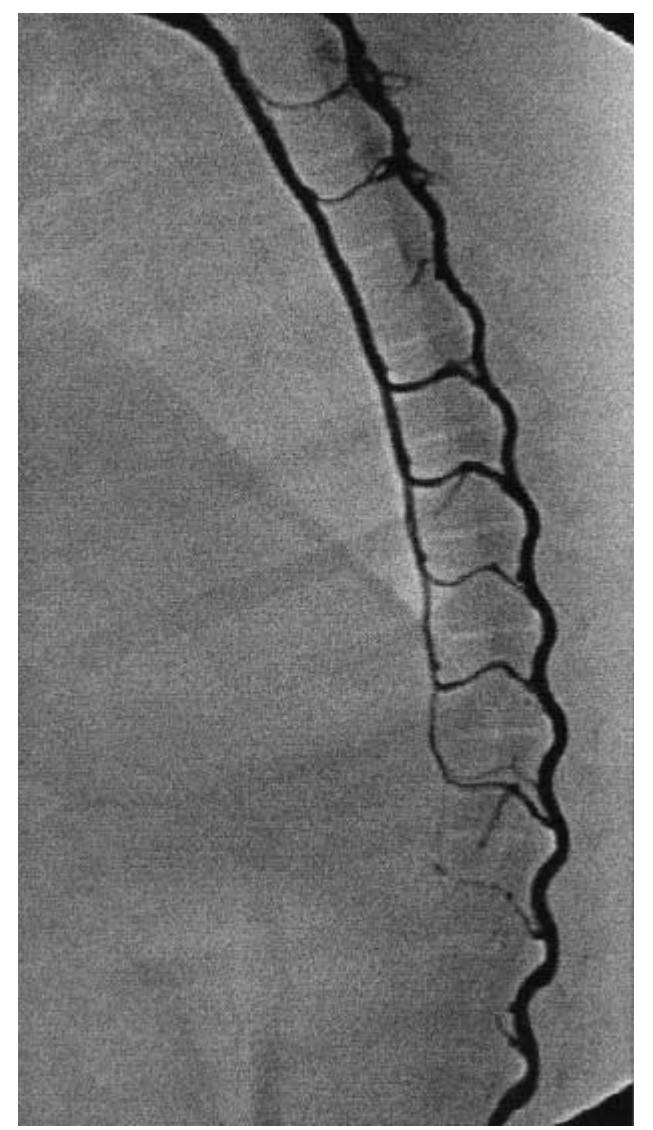

Fig 1. Venogram of lateral view of chest. Contrast injected into the accessory hemiazygos vein fills the paravertebral veins and the epidural veins.

aortic disease, and presence of aortic dissection, contributes to cord hypoxia and irreversible neurologic injury. ${ }^{7,8}$ Efforts to dampen the cascade of events leading to postoperative neuromotor deficits have focused on this multifactorial nature of spinal cord ischemic injury. Strategies such as distal aortic perfusion during crossclamping, ${ }^{3,7-11} \mathrm{CSF}$ drainage to maintain a spinal cord perfusion gradient, ${ }^{12,13}$ reimplantation of critical intercostal arteries, ${ }^{14}$ pharmacologic neuroprotection, ${ }^{15-17}$ and profound hypothermia ${ }^{18}$ have been developed to minimize spinal cord injury and preserve neuromotor function. However, none of these maneuvers, alone or in combination, has proved to be uniformly effective in the prevention of postoperative neurologic complications.

Because of the complex and oftentimes unpredictable nature of spinal cord ischemic complications, we have focused our investigative efforts on techniques to increase the tolerance of the spinal cord to ischemic intervals. In the series of experiments described here,

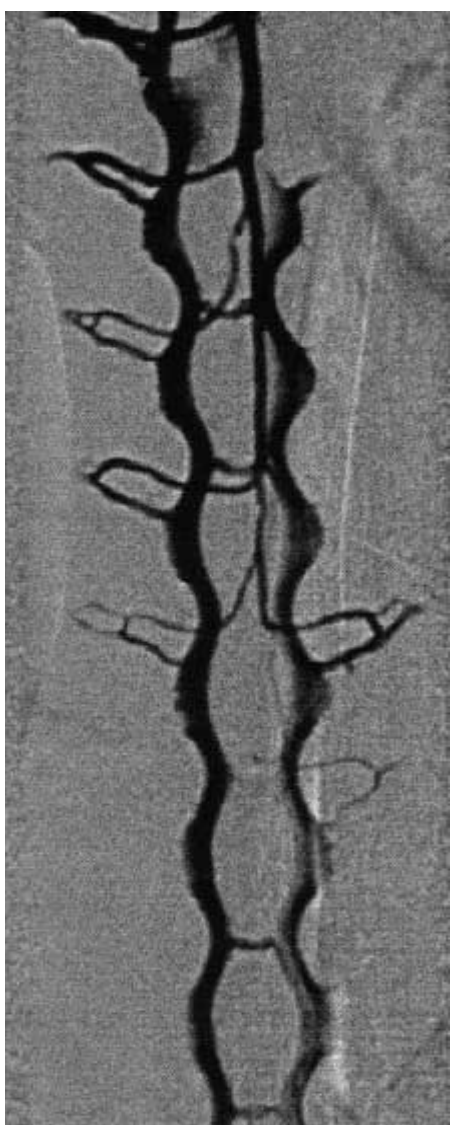

Fig 2. Venogram of anterior-posterior view of chest. Contrast injected into the accessory hemiazygos vein fills the epidural veins bilaterally.

we have developed a unique strategy of hypothermic retrograde venous perfusion of the spinal cord to prevent ischemic injury and preserve spinal cord neuromotor function. We hypothesized that this retrograde regional delivery technique would cool and preserve the spinal cord during ischemia and that the addition of adenosine would augment this neuroprotection.

\section{Methods}

Experimental protocol. Three experimental groups were investigated in a porcine model of surgery on the thoracic aorta. Each group included 6 animals that were randomly assigned. Six swine (group I) underwent thoracic aortic occlusion for 30 minutes at normothermia. A second group (group II) underwent spinal cord cooling by retrograde perfusion of the paravertebral veins with hypothermic $\left(4^{\circ} \mathrm{C}\right)$ saline solution during the 30 minutes of aortic occlusion. The spinal cords of a third group (group III) were cooled with a hypothermic adenosine solution in a similar fashion. All animals survived for 24 hours after the operation, at which time the final assessment was done. All animals received humane 
care in compliance with the "Guide for the Care and Use of Laboratory Animals" prepared by the National Institutes of Health (NIH Publication No. 86-23, revised 1985).

Experimental preparation. Adult domestic swine of either sex were anesthetized with an intramuscular injection of tiletamine and zolazepam (Telazol) $(6 \mathrm{mg} / \mathrm{kg})$, xylazine (1 $\mathrm{mg} / \mathrm{kg})$, and atropine $(0.4 \mathrm{mg} / \mathrm{kg})$. General anesthesia was maintained with $1.5 \%$ isoflurane. Through a standard left lateral thoracotomy incision, the thoracic aorta was isolated just distal to the origin of the left subclavian artery. The accessory hemiazygos vein was identified and dissected as it coursed superior to the left pulmonary hilum. The vein was ligated and divided between surgical ties, and an 18-gauge catheter was inserted into the descending portion of the vein. Retrograde perfusion of the paravertebral veins was done through this catheter. Preliminary experiments have confirmed radiographically the retrograde perfusion of the paravertebral veins (Figs 1 and 2). Temperature probes were placed nasally and rectally. A fine-needle temperature probe was also inserted in the spinal canal through a 2-cm skin incision over the spinous process of the lumbar vertebrae. Spinal temperatures were recorded with a Yellow Springs Precision 4000A temperature monitor (Yellow Springs Instrument Co Inc, Yellow Springs, Ohio).

Intravenous heparin $(200 \mathrm{U} / \mathrm{kg})$ was administered, and the thoracic aorta was crossclamped just distal to the left subclavian artery for 30 minutes. In the control group of 6 swine (group I), the hemiazygos venous catheter was not used and normothermic ischemia distal to the clamp was present. Group II animals had hypothermic $\left(4^{\circ} \mathrm{C}\right)$ saline solution infused through the venous catheter at a rate of $1000 \mathrm{~mL} / \mathrm{h}$ during the 30 minutes of aortic occlusion. In group III animals, a hypothermic adenosine solution $\left(500 \mu \mathrm{g} \cdot \mathrm{kg}^{-1}\right.$. $\mathrm{min}^{-1}$ ) was infused in a similar, retrograde, fashion. After 30 minutes, sodium bicarbonate $(1 \mathrm{mEq} / \mathrm{kg})$ was administered, the clamp was removed, and the hypothermic infusions were discontinued. The venous and arterial catheters were removed, and the chest was closed routinely. All animals were allowed to recover for 24 hours after the operation, at which time the final assessment was done. The final neurologic evaluation was graded on the basis of the Tarlov scale $(0=$ complete paralysis, $1=$ minimal movement, $2=$ stands with assistance, $3=$ stands alone, $4=$ weak walk, $5=$ normal gait). The animals were then humanely killed with an overdose injection of sodium pentobarbital.

Somatosensory evoked potential recording. Somatosensory evoked potentials (SSEPs) were monitored with an evoked potential monitor. Supramaximal stimuli (15-40 mA, pulse duration of $50 \mathrm{~ms}, 4.9$ per second) were delivered by an external bipolar stimulator placed over bilateral posterior tibial nerves. SSEP responses were recorded by subdermal electroencephalographic electrodes placed at the nasion and the inion near the midline of the scalp. A ground electrode was placed on the right thigh. Signal to noise ratios were maximized by averaging 500 consecutive responses for each SSEP tracing. The signals were further amplified and filtered with a band-pass filter set at 20 to $1000 \mathrm{~Hz}$ before processing. SSEP tracings were acquired in all three groups of animals before aortic crossclamping, every 60 seconds during clamping, and for 30 minutes after the vascular clamp was removed. Additionally, SSEP tracings were taken 24 hours after the operation. Signal amplitude and corticospinal conduction time (latency) were recorded at all time points and compared with baseline values.

Statistical analysis. Statistical analysis was done for the three groups with $\chi^{2}$ analysis and analysis of variance on SPSS software (SPSS Inc, Chicago, Ill). In addition, a multivariate repeated-measures analysis of variance was done for comparison of SSEP data between multiple time points. Significant differences were determined by the Tukey honestly significant difference test. The data are expressed as the mean plus or minus the SEM.

\section{Results}

During 30 minutes of aortic occlusion, control animals (group I) had normothermic ischemia. Intrathecal temperatures before aortic clamping measured $37.4^{\circ} \mathrm{C}$ $\pm 0.9^{\circ} \mathrm{C}$ and changed minimally throughout occlusion, measuring $36.9^{\circ} \mathrm{C} \pm 0.8^{\circ} \mathrm{C}$ after 30 minutes (Fig 3). In addition, group I animals demonstrated identical preocclusion $\left(35.1^{\circ} \mathrm{C} \pm 0.2^{\circ} \mathrm{C}\right)$ and postocclusion $\left(35.1^{\circ} \mathrm{C}\right.$ $\pm 0.1^{\circ} \mathrm{C}$ ) nasopharyngeal temperatures and similar preocclusion $\left(36.3^{\circ} \mathrm{C} \pm 0.1^{\circ} \mathrm{C}\right)$ and postocclusion $\left(35.8^{\circ} \mathrm{C}\right.$ $\pm 0.1^{\circ} \mathrm{C}$ ) rectal temperatures, further confirming systemic normothermia during aortic clamping. Hypothermic retrograde venous perfusion did cool the spinal cord in groups II and III. The spinal temperatures in animals that received retrograde hypothermic saline solution (group II) dropped $2.4^{\circ} \mathrm{C} \pm 0.1^{\circ} \mathrm{C}$, from $38.2^{\circ} \mathrm{C} \pm 0.1{ }^{\circ} \mathrm{C}$ before occlusion to $35.8^{\circ} \mathrm{C} \pm 0.2^{\circ} \mathrm{C}$ at the end of aortic clamping ( $P=.08$ vs control) (see Fig $3)$. Systemic temperatures in group II did not change: preocclusion $\left(35.8^{\circ} \mathrm{C} \pm 0.2^{\circ} \mathrm{C}\right)$ and postocclusion $\left(35.5^{\circ} \mathrm{C} \pm 0.2^{\circ} \mathrm{C}\right)$ nasopharyngeal temperatures and preocclusion $\left(36.8^{\circ} \mathrm{C} \pm 0.2^{\circ} \mathrm{C}\right)$ and postocclusion $\left(36.6^{\circ} \mathrm{C} \pm 0.2^{\circ} \mathrm{C}\right)$ rectal temperatures were similar. Retrograde hypothermic adenosine solution in group III quickly dropped the spinal temperature $4.1^{\circ} \mathrm{C} \pm$ $0.6^{\circ} \mathrm{C}$, from a starting temperature of $38.1^{\circ} \mathrm{C} \pm 0.7^{\circ} \mathrm{C}$ to an ending temperature of $34.0^{\circ} \mathrm{C} \pm 1.2^{\circ} \mathrm{C}$ at the conclusion of 30 minutes of aortic clamping $(P<.01 \mathrm{vs}$ control) (see Fig 3 ). The spinal cooling in group III did not cause significant changes in systemic temperatures. Nasopharyngeal temperatures before occlusion $\left(35.3^{\circ} \mathrm{C} \pm 0.2^{\circ} \mathrm{C}\right)$ and after occlusion $\left(34.7^{\circ} \mathrm{C} \pm 0.1^{\circ} \mathrm{C}\right)$ and rectal temperatures before occlusion $\left(36.5^{\circ} \mathrm{C} \pm\right.$ $\left.0.2^{\circ} \mathrm{C}\right)$ and after occlusion $\left(35.9^{\circ} \mathrm{C} \pm 0.3^{\circ} \mathrm{C}\right)$ remained constant $(P>.2)$.

All animals tolerated the period of aortic occlusion and survived the 24-hour recovery period after the 


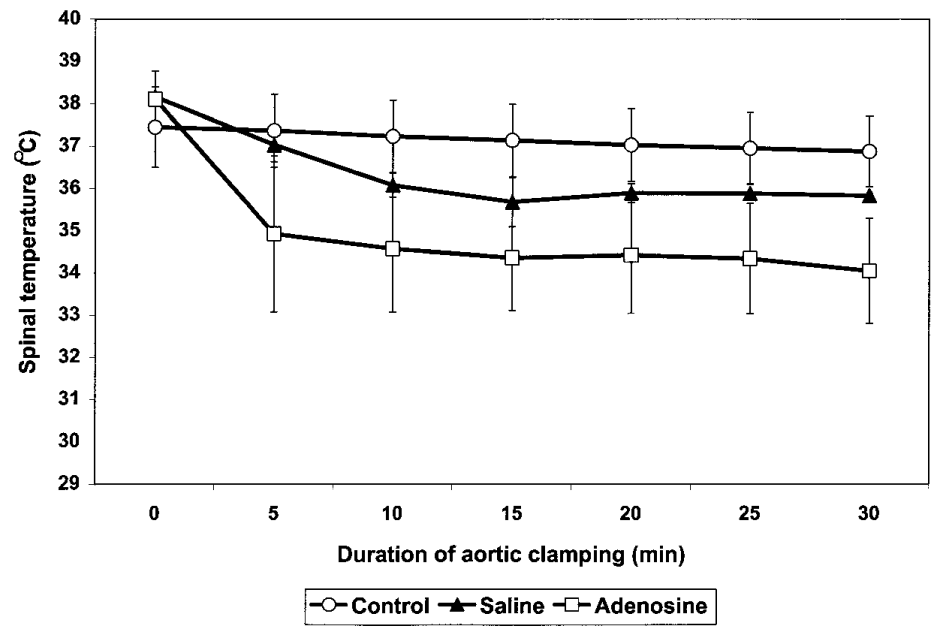

Fig 3. Spinal temperatures during aortic crossclamping. Retrograde venous perfusion of the spinal cord with hypothermic adenosine (group III) quickly cooled the spinal cord and lowered spinal temperatures by $4.1^{\circ} \mathrm{C}$ after 30 minutes of aortic occlusion $(P<.01)$.

Table I. Changes in SSEPs after thoracic aortic occlusion and cessation of occlusion

\begin{tabular}{lcccc}
\hline & Group I (control) & Group II (saline) & Group III (adenosine) & P value vs control \\
\hline $\begin{array}{l}\text { Loss of SSEPs }(\mathrm{min}) \\
\text { Amplitude }(\mu \mathrm{V})\end{array}$ & $10.6 \pm 1.4$ & $6.9 \pm 1.2$ & $7.0 \pm 0.8$ & .06 \\
$\quad$ & $0.58 \pm 0.1 .5$ & $0.45 \pm 0.04$ & & \\
$\quad$ Baseline & 0 & $0.55 \pm 0.03$ & $0.61 \pm 0.16$ & .67 \\
30-min reperfusion & $0.05 \pm 0.02$ & $0.39 \pm 0.06$ & $0.40 \pm 0.10$ & .001 \\
24-h reperfusion & & & & .003 \\
Latency (ms) & $-31.76 \pm 1.21$ & $32.08 \pm 3.44$ & $31.23 \pm 3.22$ & .90 \\
$\quad$ Baseline & - & $33.58 \pm 0.89$ & $32.96 \pm 2.66$ & \\
30-min reperfusion & & & $31.55 \pm 0.90$ & \\
24-h reperfusion & & & \\
\hline
\end{tabular}

operation for final neurologic evaluation. Spinal cooling without systemic hypothermia significantly improved neurologic Tarlov scores in group III (4.8 \pm $0.2)$ and group II $(3.8 \pm 0.4)$ as compared with group I scores $(1.3 \pm 0.6)(P<.001)$. Furthermore, 5 of the 6 animals in group III displayed normal neurologic function at 24 hours after the operation (Tarlov score 5), whereas only 1 animal in group II and no animals in group I did $(P=.005)$. The only animal in group III that showed evidence of a motor deficit at 24 hours after the operation displayed a slightly weakened walk and was given a Tarlov score of 4 at this early recovery stage. In contrast, normothermic control animals (group I) displayed neurologic damage with either complete motor lesions (Tarlov 0) or recovery of minimal voluntary movement (Tarlov 1) after the operation.

SSEP data were recorded in all animals before aortic clamping, during occlusion, during recovery, and 24 hours after the operation (Table I). After occlusion of the thoracic aorta in the control animals (group I), the amplitudes of the potentials gradually decreased and the latencies became prolonged. In group I, SSEPs disappeared at a mean occlusion time of $10.6 \pm 1.4 \mathrm{~min}-$ utes. Retrograde perfusion cooling of the spinal cord resulted in a more rapid cessation of neural transmission with loss of SSEPs at $6.9 \pm 1.2$ minutes in group II and $7.0 \pm 0.8$ minutes in group III $(P=.06)$. After release of the aortic crossclamp, SSEPs failed to reappear in the normothermic control animals of group I after 30 minutes of reperfusion, and the amplitudes of the SSEPs only recovered to $10 \% \pm 8 \%$ of baseline after 24 hours of recovery. In group II, SSEPs returned in all animals after occlusion was discontinued. The earliest reappearance of SSEPs in group II occurred at 4 minutes of reperfusion, the latest occurred at $11 \mathrm{~min}-$ utes, and the amplitudes of the SSEPs were 90\% $\pm 14 \%$ of baseline after 24 hours of reperfusion $(P=.01 \mathrm{vs}$ group I). All group III animals also had SSEPs quickly 
reappear after the end of occlusion, and all signals returned within 5 minutes of reperfusion. After 24 hours of recovery, the latencies of the SSEPs had shifted back to normal and the amplitudes of the peaks recovered to $85 \% \pm 25 \%$ of baseline ( $P=.01$ vs group I) (see Table I)

\section{Discussion}

Spinal cord ischemic complications after surgical procedures on the thoracic aorta remain an unsolved problem in modern vascular surgery. Several protective strategies have been developed either to maintain the blood supply of the spinal cord or to increase the ischemic tolerance of the cord. Hypothermia has been a widely studied neuroprotective adjunct in the effort to extend the tolerance of the spinal cord to the hypoxic state. ${ }^{18-22}$ Although the neuroprotective mechanism of hypothermia is presumed to be secondary to decreased tissue metabolism and decreased oxygen demand, the effect of hypothermia may be more complex and involve membrane stabilization and reduced release of excitatory neurotransmitters. ${ }^{18}$ The best clinical method to produce spinal hypothermia remains unclear. The technique of cardiopulmonary bypass with intervals of circulatory arrest creates profound spinal cord hypothermia and has been shown to protect the spinal cord during aortic repair. ${ }^{18}$ This profound hypothermia clearly extends the window of ischemic tolerance to complete complex aortic repairs, but enthusiasm is not widespread for descending aortic operations, principally because of the threat of myocardial irritability, coagulopathy, and pulmonary dysfunction. ${ }^{7}$ These complications have encouraged increased investigations of alternative methods to safely and effectively induce spinal hypothermia.

There is experimental evidence from several laboratories including ours verifying that regional hypothermic perfusion of the spinal cord protects it from ischemic injury. ${ }^{19-21}$ One technique of regional cooling uses the infusion of a hypothermic solution directly into the isolated aortic segment or the intercostal arteries supplying blood to the cord. Colon and colleagues ${ }^{20}$ documented that such a technique lowered the spinal cord temperature by $5.8^{\circ} \mathrm{C}$ after 30 minutes. This method of spinal cooling depends on perfusion of the critical intercostals that supply the area of spinal cord at risk, and it requires a period of aortic hypothermic perfusion during which the aorta is clamped but repair is delayed.

Recently, new techniques of regional hypothermic perfusion with the solution delivered directly to the epidural or intrathecal space have achieved spinal cool- ing and preservation of neuromotor function during aortic crossclamping. ${ }^{22}$ Cambria and Davison ${ }^{22}$ have reported CSF temperatures of $23^{\circ} \mathrm{C}$ to $25^{\circ} \mathrm{C}$ after 30 to 45 minutes of epidural infusion before aortic crossclamping. The epidural infusion does, however, lead to an increase in CSF pressure, one of the factors implicated in the pathophysiologic makeup of spinal cord ischemic injury, and spinal cord injury has occurred in this setting.

In this set of experiments, we have proposed a simple method of protecting the spinal cord during ischemia that uses the concept of hypothermic retrograde venous perfusion, analogous to retrograde cardiac perfusion with cold cardioplegic solution and retrograde cerebral perfusion during circulatory arrest. Retrograde venous perfusion with hypothermic saline solution alone led to a small drop in spinal temperature, which significantly improved neurologic Tarlov scores after recovery. In a small-animal model, we discovered that this modest temperature change with hypothermic saline solution led to improved neurologic outcomes as compared with results after retrograde perfusion of saline solution at body temperature. ${ }^{23}$ With retrograde delivery of a hypothermic adenosine solution to the paravertebral veins during 30 minutes of aortic crossclamping, we rapidly lowered the spinal cord temperature by $4.1^{\circ} \mathrm{C}$ and preserved normal postoperative neuromotor function without incurring systemic complications, local spinal cord complications, or operative delay.

The addition of adenosine to preservation solutions is not unique. Adenosine has been successfully incorporated into a variety of solutions for preservation of the heart, liver, kidneys, and pancreas for transplantation and other surgical procedures. ${ }^{24}$ Adenosine has also been shown to have specific neuroprotective effects, and previous work in our laboratory has demonstrated spinal cord protection with a hypothermic adenosine solution in a rabbit model of spinal cord ischemia. ${ }^{21,23,25}$ Activation of both A1- and A2-adenosine receptors likely dictates the beneficial effects of adenosine on ischemic neural tissue. A1-receptor activation decreases neuronal excitability and limits the damaging influx of calcium through voltage-gated channels, and adenosine has been shown to inhibit the release of excitatory neurotransmitters. ${ }^{26,27}$ In addition, stimulation of A2receptors causes vasodilation and inhibits platelet aggregation, neutrophil activation, and subsequent free radical production, thereby reducing reperfusion injury after an ischemic interval. ${ }^{25,26}$ Vasodilation might be particularly useful in the setting of spinal cord ischemia, because it might increase collateral blood flow to the spinal cord and, in our model, it might 
enhance spinal cooling. In this set of experiments, animals that underwent hypothermic retrograde perfusion of the spinal cord clearly outperformed control animals after spinal cord ischemia. The addition of adenosine to the hypothermic solution led to lower spinal temperatures, improved neurologic Tarlov scores, and significantly improved preservation of normal neuromotor function.

The sensitivity of evoked potential recording to monitor the disruption of spinal cord blood supply has led to the emergence of SSEPs as a tool for the intraoperative assessment of spinal cord perfusion and viability during proximal aortic crossclamping. ${ }^{8,10,11}$ SSEPs are responsive to subtle changes in sensory conduction caused by oxygen deprivation of the posterior and lateral spinal columns. After the onset of aortic crossclamping, decreased amplitudes and prolonged latencies of the SSEP signals are indicative of impaired posterior and lateral spinal column sensory conduction and compromised spinal cord perfusion. If such changes persist, spinal cord ischemia and a flat-line SSEP response occur, indicating a total absence of spinal conduction. This is defined as a type I SSEP response. ${ }^{8}$ In the present study, the induction of spinal cord ischemia under normothermic conditions resulted in a type I SSEP response with progressive deterioration of the SSEP components and loss of the SSEP signal after just over 10 minutes of aortic occlusion. The signals failed to return after 30 minutes and 24 hours of reperfusion. This pattern of deterioration of spinal conduction correlated with postoperative paraplegia in the control animals.

In our model, spinal cord ischemia after aortic crossclamping resulted in loss of SSEPs in all experimental groups. These signals were lost sooner in the presence of modest reductions in spinal temperature with the addition of retrograde venous perfusion cooling of the spinal cord. During reperfusion of cooled spinal cords in groups II and III, the SSEP signals returned and reached $85 \%$ to $90 \%$ of baseline values after 24 hours of recovery. This pattern of spinal cooling and a more rapid extinction of the evoked response during ischemia also correlated with improved neurologic outcomes after aortic occlusion, inasmuch as the Tarlov scores in both groups II and III were significantly better than those in control group I. These results suggest that the efficacy of regional spinal hypothermia in the prevention of spinal cord injury may be a result of a reduction in the metabolic and electrical activity of the spinal cord during ischemia.

Adenosine added to the hypothermic solution in group III clearly preserved normal motor function better than hypothermic saline solution alone. We have previously shown in a small-animal model of retrograde venous perfusion that whereas warm adenosine and hypothermic saline solution each individually improve neurologic function after ischemia compared with results in control animals, their additive effect is significantly more protective. ${ }^{21}$ In group II animals, the return of SSEPs during reperfusion after ischemia symbolized preservation of the sensory conductance of the spinal cord but did not represent complete recovery of normal neuromotor function. Hypothermic adenosine in group III preserved sensory conductance and provided complete protection of neuromotor function. Whether hypothermic adenosine more completely protects the anterior motoneuronal tracts during ischemia or prevents secondary injuries to the spinal cord motor system during reperfusion is a question that mandates further study.

Retrograde venous perfusion of the spinal cord with hypothermic adenosine cools the cord and produces a more rapid electrical silence of the spinal conductive pathways than ischemia alone after aortic crossclamping. This phenomenon clearly provides a tolerable period of ischemia resulting from the temporary reduction in spinal cord perfusion, after which normal neuromotor function returns. However, because the etiology of spinal cord ischemic injury is multifactorial, it is unlikely that any single intervention will completely eliminate the complication of postoperative paraplegia. We believe that hypothermic retrograde venous perfusion of the spinal cord is a promising component of the multimodality approach necessary to achieve optimal spinal cord protection. The similarities of human paravertebral anatomy to our experimental conditions create the possibility of clinical use of hypothermic retrograde venous perfusion during thoracic aortic operations. This intervention might provide valuable time during aortic occlusion to perform complex aortic reconstructions and to complete additional intraoperative adjuncts of spinal cord protection, such as critical intercostal artery reimplantation. Further studies are warranted to determine the maximum period of ischemic tolerance our technique provides and to investigate clinical correlation.

\section{REFERENCES}

1. Svensson LG, Crawford ES, Hess KR, Coselli JS, Safi HJ. Experience with 1509 patients undergoing thoracoabdominal aortic operations. J Vasc Surg 1993;17:357-70.

2. Cambria RP, Davison JK, Zannetti S, L'Italien G, Atamian S. Thoracoabdominal aneurysm repair: perspectives over a decade with the clamp-and-sew technique. Ann Surg 1997;226:294-305.

3. Coselli JS. Thoracoabdominal aortic aneurysms: experience with 372 patients. J Card Surg 1994;9:638-47. 
4. Coselli JS, Plestis KA, LaFrancesca S, Cohen S. Results of contemporary surgical treatment of descending thoracic aortic aneurysms: experience in 198 patients. Ann Vasc Surg 1996;10: 131-7.

5. Lawrie GM, Earle N, DeBakey ME. Evolution of surgical techniques for aneurysms of the descending thoracic aorta: twentynine years experience with 659 patients. J Card Surg 1994;9:64861.

6. Mauney MC, Tribble CG, Cope JT, Tribble RW, Spotnitz WD, Kron IL. Is clamp and sew still viable for thoracic aortic resection? Ann Surg 1996;223:534-43.

7. Robertazzi RR, Cunningham JN. Intraoperative adjuncts of spinal cord protection. Semin Thorac Cardiovasc Surg 1998;10: 29-34.

8. Robertazzi RR, Cunningham JN. Monitoring of somatosensory evoked potentials: a primer on the intraoperative detection of spinal cord ischemia during aortic reconstructive surgery. Semin Thorac Cardiovasc Surg 1998;10:11-7.

9. Robertazzi RR, Acinapura AJ. The efficacy of left atrial to femoral artery bypass in the prevention of spinal cord ischemia during aortic surgery. Semin Thorac Cardiovasc Surg 1998;10: 67-71.

10. Galla JD, Ergin MA, Sadeghi AM, Lansman SL, Danto J, Griepp RB. A new technique using somatosensory evoked potential guidance during descending and thoracoabdominal aortic repairs. J Card Surg 1994;9:662-72.

11. Schepens MA, Boezeman EH, Hamerlijnck RP, terBeek H, Vermeulen FE. Somatosensory evoked potentials during exclusion and reperfusion of critical aortic segments in thoracoabdominal aortic aneurysm surgery. J Card Surg 1994;9:692-702.

12. Crawford ES, Svensson LG, Hess KR, Shenaq SS, Coselli JS, Safi HJ, et al. A prospective randomized study of cerebrospinal fluid drainage to prevent paraplegia after high-risk surgery on the thoracoabdominal aorta. J Vasc Surg 1991;13:36-45.

13. Kazama S, Masaki Y, Mayuyama Y, Ishihara A. Effect of altering cerebrospinal fluid pressure on spinal cord blood flow. Ann Thorac Surg 1994;58:112-5.

14. Svensson LG, Hess KR, Coselli JS, Safi HJ. Influence of segmental arteries, extent, and atriofemoral bypass on postoperative paraplegia after thoracoabdominal aortic operations. J Vasc Surg 1994;20:255-62.

15. Qayumi AK, Janusz MT, Jamieson WRE, Lyster DM. Pharmacologic interventions for prevention of spinal cord injury caused by aortic crossclamping. J Thorac Cardiovasc Surg 1992; 104:256-61.

16. Rokkas CK, Helfrich LR, Lobner DC, Choi DW, Kouchoukos NT. Dextrorphan inhibits the release of excitatory amino acids during spinal cord ischemia. Ann Thorac Surg 1994;58:312-20.

17. Ehrlich M, Knolle E, Ciovica R, Bock P, Turkof E, Grabenwoger $\mathrm{M}$, et al. Memantine for prevention of spinal cord injury in a rabbit model. J Thorac Cardiovasc Surg 1999;117:285-91.

18. Rokkas CK, Kouchoukos NT. Profound hypothermia for spinal cord protection in operations on the descending thoracic and thoracoabdominal aorta. Semin Thorac Cardiovasc Surg 1998;10: 57-60.

19. Coles JG, Wilson GJ, Sima AF, Klement P, Tait GA, Williams WG, et al. Intraoperative management of thoracic aortic aneurysm. J Thorac Cardiovasc Surg 1983;85:292-9.

20. Colon R, Frazier OH, Cooley DA, McAllister HA. Hypothermic regional perfusion for protection of the spinal cord during periods of ischemia. Ann Thorac Surg 1987;43:639-43.
21. Herold JA, Kron IL, Langenburg SE, Blackbourne LH, Tribble CG. Complete prevention of postischemic spinal cord injury by means of regional infusion with hypothermic saline and adenosine. J Thorac Cardiovasc Surg 1994;107:536-42.

22. Cambria RP, Davison JK. Regional hypothermia for prevention of spinal cord ischemic complications after thoracoabdominal aortic surgery: experience with epidural cooling. Semin Thorac Cardiovasc Surg 1998;10:61-5.

23. Parrino PE, Kron IL, Ross SD, Shockey KS, Fisher MJ, Gaughen JR, et al. Spinal cord protection during aortic crossclamping using retrograde venous perfusion. Ann Thorac Surg 1999;67: 1589-95.

24. Southard JH, vanGulick TM, Ametani MS, Vreugdenhil PK, Lindell SL, Pienaar BL, et al. Important components of the UW solution. Transplantation 1990;49:251-7.

25. Marangos PJ, vonLubitz DAG, Daval JL, Deckert J. Adenosine: its relevance to the treatment of brain ischemia and trauma. Prog Clin Biol Res 1990;361:331-49.

26. Schubert P, Kreutzberg GW. Cerebral protection by adenosine. Acta Neurochir Suppl (Wien) 1993;57:80-8.

27. Simpson RE, O'Regan MH, Perkins LM, Phillis JW. Excitatory transmitter amino acid release from the ischemic rat cerebral cortex: effects of adenosine receptor agonists and antagonists. J Neurochem 1992;58:1683-90.

\section{Discussion}

Dr Verdi J. DiSesa (Chicago, Ill). Do you have any evidence that you are actually perfusing the spinal cord through these veins?

Dr Ross. The evidence that we have includes our radiographic demonstration of bilateral filling of the paravertebral veins and epidural veins after injection of contrast dye into the hemiazygos vein. In addition, perfusion of this spinal venous plexus with our hypothermic solutions produces a decrease in intrathecal temperatures. Therefore the CSF and the spinal cord are regionally accessible by this technique.

Dr James L. Cox (Washington, DC). You are comparing the degree of myocardial protection that we achieve with cardioplegia with your findings of neurologic protection in the spinal cord, and yet you decreased the temperature in the group receiving saline solution by only $2^{\circ} \mathrm{C}$ and in the group receiving adenosine by only $4^{\circ} \mathrm{C}$. If we achieve only that level of hypothermia in the heart, the electrical activity is basically unchanged. How do you explain the rapidity with which electrical activity was lost in the spinal cord at those temperatures?

Dr Ross. We were also surprised by the loss of electrical activity in the spinal cord with the small decrease in spinal temperature. Neurologic tissue is clearly not identical to cardiac muscle in this respect. Dr Cooley has demonstrated that a spinal temperature drop of $5.8^{\circ} \mathrm{C}$ leads to improved neurologic function after an operation, and we have demonstrated that this decrease in temperature does produce neurologic electrical silence that correlates with a lower incidence of neurologic complications.

Dr Cox. It would be fairly simple to decrease the temperature about $2^{\circ} \mathrm{C}$ to $3^{\circ} \mathrm{C}$ clinically by a variety of techniques, probably even without cardiopulmonary bypass. Do you 
think that there is any advantage to doing this through the venous system as opposed to the arterial system?

Dr Ross. The advantage of the use of the venous system in this situation is the avoidance of complications associated with other techniques that are used to produce either systemic or regional hypothermia. Obviously, circulatory arrest with cardiopulmonary bypass allows profound systemic hypothermia, but it has numerous associated complications.

Other techniques have been developed to avoid these systemic complications and produce regional spinal cooling, but these methods also carry potential complications. Direct epidural cooling has been shown to protect neurologic function, but this epidural infusion increases CSF pressure, and this increase in pressure may be a factor that causes spinal cord ischemic injury. Another technique is perfusion of the isolated aortic segment or the intercostal arteries. The problems with this method are correct identification of the critical intercostal arteries and delay of operative repair. In this situation, the aortic crossclamp times are potentially prolonged unnecessarily while the hypothermic solution is infusing.

Retrograde perfusion through the venous system produces regional spinal cooling but does not affect CSF pressure and does not cause longer aortic crossclamp times.

Professor Alain F. Carpentier (Paris, France). What pressures and flow rates do you use during your perfusion?

Dr Ross. In this initial set of experiments we infused our solutions through a normal intravenous pump system at a flow rate of $1 \mathrm{~L} / \mathrm{h}$ during the 30 minutes of aortic occlusion. We do not have data at this time on the pressure levels in the hemiazygos vein during the infusion.

Dr Hazim J. Safi (Houston, Tex). As we know, the systemic cooling of profound hypothermia carries a high risk of trauma to the lungs and it does not prevent paraplegia. When we used retrograde venous perfusion in a dog model, we did not include cooling and we did not use adenosine and we found that results were not improved either combined with or just compared with distal aortic perfusion and CSF drainage. What is your next step with this method of perfusion and do you plan to use it with additional adjuncts?

Dr Ross. That certainly is our hope. We are not proposing that this technique is the only thing that needs to be done to suddenly achieve complete neurologic protection. However, we do think that retrograde hypothermic perfusion will provide a period of tolerable ischemia during which other neuroprotective adjuncts might also be used, particularly reimplantation of critical intercostal arteries, distal aortic perfusion, and CSF drainage. We believe that more time would be available to implant separate Carrel patches and perform difficult procedures safely and without neurologic complications.
Dr Bradley S. Allen (Oak Lawn, Ill). To follow up on Dr Cox's question, there was very little reduction in temperature in the adenosine group, and yet you found remarkable improvement. Does that not imply that the improvement is secondary to one of the other beneficial properties of adenosine, such as inhibiting adherence of activated white cells, rather than its ability to lower temperature?

Dr Ross. That certainly is a distinct possibility. Adenosine is no stranger to preservation solutions for various organ systems. As you mention, adenosine has neuroprotective effects both through A1-receptors that decrease neuronal excitability and through A2-receptors that inhibit platelet aggregation, decrease neutrophil activation, and reduce reperfusion injury.

In a previous study, we used a rabbit model of spinal cord ischemia and divided the groups into those receiving warm saline solution, warm adenosine, cold saline solution, or cold adenosine. We found a stepwise progression of neurologic protection in which warm adenosine did protect function better than warm saline solution alone, but it did not achieve the same degree of neurologic protection after operation that cold adenosine did in the rabbit model. Thus we do believe that the combination of hypothermia and adenosine provides more protection than just adenosine alone.

Dr G. Hossein Almassi (Milwaukee, Wis). Why did you choose 30 minutes of clamping? Do you think the benefit that you saw in the adenosine group would persist if you had carried out the clamping to an hour, for example?

Second, did you measure the CSF pressure? You alluded to the increase in CSF pressure with the use of direct intrathecal cooling. Do you have any data about the CSF pressure in each of your experimental groups?

Dr Ross. To answer your first question, we chose $30 \mathrm{~min}$ utes of aortic clamping on the basis of other experimental evidence in the literature demonstrating that this duration of aortic occlusion reliably produced neurologic injury in the swine model. In our initial control experiments, we also found significant neurologic injury after 30 minutes of clamping, and we then tested our intervention using this period. We are planning future studies with longer crossclamp times to see how long this tolerable period of ischemia may be extended.

As to your second question, we did measure CSF pressures. We found a typical response in that CSF pressures rose during aortic clamping and decreased again after cessation of aortic occlusion. We did not perform CSF drainage during our procedures. The normal CSF pressures in the porcine model started between 11 and $13 \mathrm{~cm} \mathrm{H}_{2} \mathrm{O}$ and increased to approximately 17 to $19 \mathrm{~cm} \mathrm{H}_{2} \mathrm{O}$ with aortic clamping. There was no difference in this pattern of CSF pressures between the control and hypothermic groups. 